\title{
APUNTES SOBRE CONSERVADURISMO Y NEOCONSERVADURISMO EN LA EDUCACIÓN VENEZOLANA
}

\author{
Notes on conservatism and neoconservatism in venezuelan education
}

\author{
Apontamentos sobre conservadorismo e neoconservadorismo na educação \\ venezuelana
}

\begin{abstract}
Resumen
Abordar la influencia de una determinada corriente de pensamiento en un ámbito como la educación constituye una tarea compleja. Este esfuerzo se hace más complejo cuando se amplía el foco y se descubre el entrecruce de ideas, enfoques y prácticas que se fraguan para darle sentido a una praxis que ocupa un importante y vasto periodo histórico. Más aún si este propósito está condicionado por las limitaciones de un ensayo sobre una realidad concreta, en este caso como la venezolana. Esta advertencia no es un asunto menor, si se hurga en la impronta conservadora de las concepciones pedagógicas que primaron en la conformación del ethos educativo venezolano en el decurso de su historia. Ahora bien, esta breve y rápida referencia, incorpora en el análisis a su "antítesis", el liberalismo político y económico. No sólo por la pretendida dialéctica que en principio mantienen, sino porque la configuración histórica de esta praxis política en el país se fundamenta en el tránsito situacional de los grupos de poder desde una u otra perspectiva ideológica. Por lo anterior, dadas las advertencias del caso, el presente trabajo se propuso hacer una apretada reflexión sobre algunos aspectos significativos que revelan la disputa histórica en el seno de la educación nacional, por imprimir el sentido que favoreciera los intereses de los sectores en pugna. De soslayo, permitió prefigurar aspectos políticos, sociales, económicos y culturales que gobernaron cada momento transitado hasta nuestros días, atisbando rasgos del neoconservadurismo hoy en boga.
\end{abstract}

PALABRAS CLAVE: Conservadurismo. Neoconservadurismo. Liberalismo. Educación. Proceso histórico.

\begin{abstract}
Addressing the influence of a certain current of thought in a field such as education is a complex task. This effort becomes more complex when the focus is broadened and the intersection of ideas, approaches and practices that forges to make sense of a praxis that occupies an important and vast historical period is discovered. Even more so if this purpose is conditioned by the limitations of an

\footnotetext{
* Doutorado em Educação. Professor da Universidad Nacional Simón Rodríguez, Caracas-Venezuela. Sede Rectorado: Santa Fe Norte, Av. José María Vargas, Torre del Colegio Médicos, piso 7, Caracas-Venezuela, código postal: 1080. RIF - G2000006. Teléfonos: 0212 761.92.84/68.80/59.66. E-mail: shcarvajal@gmail.com. Orcid: http://orcid.org./0000-0002-7298-741X.
} 
essay on a specific reality, in this case like the Venezuelan one. This warning is not a minor matter, if one delves into the conservative imprint of the pedagogical conceptions that prevailed in the shaping of the Venezuelan educational ethos in the course of its history. Now, this brief and quick reference incorporates into the analysis its "antithesis", political and economic liberalism. Not only because of the alleged dialectic that they maintain in principle, but because the historical configuration of this political praxis in the country is based on the situational transit of power groups from one or another ideological perspective. Therefore, given the warnings in the case, this paper set out to make a tight reflection on some significant aspects that reveal the historical dispute within national education, to impress the sense that favored the interests of the sectors in conflict. Sideways, it allowed to prefigure political, social, economic and cultural aspects that governed every moment traveled until today, glimpsing features of neo-conservatism in vogue today.

KEYWORDS: Conservatism. Neoconservatism. Liberalism. Education. Historical process.

\section{Resumo}

Abordar a influência de uma certa corrente de pensamento em um campo como a educação é uma tarefa complexa. Esse esforço se torna mais complexo quando o foco é ampliado e a intersecção de ideias, abordagens e práticas forjam para dar sentido a uma práxis que ocupa um período histórico importante e vasto. Ainda mais se esse objetivo estiver condicionado pelas limitações de um ensaio sobre uma realidade específica, neste caso como o venezuelano. Esse aviso não é um assunto menor, se alguém se aprofundar na impressão conservadora das concepções pedagógicas que prevaleceram na formação do ethos educacional venezuelano no curso de sua história. Agora, essa referência breve e rápida incorpora na análise sua "antítese", liberalismo político e econômico. Não apenas pela suposta dialética que eles mantêm em princípio, mas porque a configuração histórica dessa práxis política no país se baseia no trânsito situacional de grupos de poder de uma ou outra perspectiva ideológica. Portanto, dadas as advertências do caso, este artigo se propôs a refletir fortemente sobre alguns aspectos significativos que revelam a disputa histórica na educação nacional, para impressionar o sentido que favoreceu os interesses dos setores em conflito. Portanto, permitiu prefigurar aspectos políticos, sociais, econômicos e culturais que governaram todos os momentos, vislumbrando características do neoconservadorismo em voga hoje.

PALAVRAS-CHAVE: Conservadorismo. Neoconservadorismo. Liberalismo. Educação. Processo histórico.

\section{INTRODUCCIÓN}

La secular aspiración de "conservar las sanas doctrinas" a las que aspiraba Chateaubriand ${ }^{1}$ como expresión de un tiempo convulso, de transición, liderado por la burguesía liberal europea en el transcurso de los siglos XVIII y XIX, pareciera que sigue sonando como un ritornello permanente. Esas "sanas doctrinas" que, de manera imperecedera perviven y que reaparecen en cada momento de crisis, sea ésta real o construida por cualquier tipo de relato interesado, también adquieren cuerpo en nuestro

\footnotetext{
${ }^{1}$ François-René, vizconde de Chateaubriand. Fue un político, diplomático y escritor, reconocido como el precursor del romanticismo literario francés.
}

Educação e Fronteiras On-Line, Dourados/MS, | v. 10, n.30, p. 42-60, set /dez 2020 
tiempo en la interpelación moral que hace la sociedad a las instituciones y por tanto a los presupuestos que las soportan; estableciendo así una conexión intemporal con aquellas prácticas y aspiraciones hegemónicas de las élites y su naturalización de la vida social, por tanto, del poder.

Tales doctrinas a las que hacía referencia el pensador francés enfatizaban en la naturalización del orden social, como algo dado, jerarquizado y excluyente, en cuya cúspide debían mantenerse siempre los "elegidos" como resultado de la emanación providencial de ese orden natural. Orden al que Cicerón asociaba con Dios, porque según el jurista y pensador romano a pesar de no verlo, a éste se le reconocía en sus obras.

Este proceso representa el reacomodo de las élites en oposición al movimiento telúrico que significó la revolución francesa para todos los estamentos constituidos de entonces: monarquía, Iglesia, aristocracias y demás signos de la época, que corporizaban y definían al antiguo régimen medieval. De igual manera, dejaba en evidencia la contradicción entre la visión tomista de la sociedad y su acervo ideológico - cultural respecto al indetenible proceso de secularización que operaba en el interior de éstas, con el liberalismo como punta de lanza.

Volviendo con Chateaubriand, cabe resaltar que la referencia que tenía como propósito no una defensa a ultranza de las viejas instituciones, sino que aludía a la cuestión intelectual, de allí la reivindicación de las que llamaba "sanas doctrinas". Las instituciones pueden cambiar, lo que debe quedar inmutable son las ideas que hegemonizan la vida intelectual y cultural de la época, es decir, las esencias "fundamentales" derivadas de la tradición.

Sin embargo, a la luz de los tiempos aquellas ideas referidas a la defensa a ultranza del viejo régimen, es decir, del orden indiscutido emanado de la razón teologal y materializado por la Iglesia y las monarquías absolutistas, han ido evolucionando manteniendo sí la esencia de su legado: la hegemonía política y, fundamentalmente, cultural sobre las sociedades.

Klaus Von Beyme ${ }^{2}$ sostiene que es a partir de 1795, años después de la revolución francesa, cuando comienza a utilizarse la palabra conservador (conservadurismo) en Francia, luego experimentando una expansión de su uso por el resto del continente europeo.

José María Marco afirma que:

El conservadurismo es la expresión moral y política del sentimiento de pérdida de un orden previo: el orden del antiguo régimen o un orden orgánico vertebrado mediante formas diversas de solidaridad comunitaria como son la familia, el vecindario, la parroquia o los gremios.

Queda aquí reflejado el profundo escepticismo respecto a la idea de progreso, así como un enraizamiento con las tradiciones y costumbres, apegadas éstas a una autoridad

\footnotetext{
${ }^{2}$ VON BEYNE, K. El Conservadurismo. Revista de Estudios Políticos (Nueva Época). Número 43, enero -
} febrero 1985, p. 9. 
suprema, jerárquica e indiscutible que revela, aun en nuestros tiempos, un orden moral y, en consecuencia, cultural, inmutable e incuestionable. Por tanto, la educación constituye un espacio que el pensamiento secular conservador considera como propio, territorio indisputable, coto cerrado para cualquier otra "aventura" intelectual y/o especulación; puesto que en ésta descansa la esperanza de su propia pervivencia.

Sin embargo, el pensamiento conservador no puede concebirse como un bloque homogéneo, sin fisuras ni tendencias; en éste cohabitan diversas perspectivas intelectuales y prácticas que, en algunos casos, enfatizan aspectos espirituales, religiosos o tradicionalistas mientras otros ponen el acento en lo material, es decir, en la economía y el poder. Sin desdeñar aspectos identitarios que en la actualidad son rasgos que los cohesionan en su proyecto político intelectual con vocación de poder, tales como: oposición rotunda a la intervención del Estado, defensa y promoción de la propiedad privada, estímulo a la descentralización administrativa.

A estos aspectos, habría que agregar otros de carácter fundantes de la praxis conservadora, asociados a su oposición rotunda a las ideas de igualdad y redistribución de la riqueza material. Estas ideas se sustentan en la concepción de un orden social jerárquico, en el que deben existir instituciones fuertes bajo el "imperio" de la ley, así como diversas formas de autoridad en un contexto social que reconoce que el hombre no fue creado ni igual ni libre. Es decir, parafraseando a Kirk, prevalece la "Creencia en el orden trascendental, es decir, la creencia en la existencia de un cuerpo de leyes naturales que establece lineamientos para la sociedad y la conciencia." 3 En otras palabras, la existencia de "...verdades y valores absolutos hacia los cuales el hombre debe dirigirse", como afirmaría Meyer ${ }^{4}$.

\section{La fuerza de las ideas conservadoras en suelo americano}

Pensar sobre la influencia conservadora y, en consecuencia, neoconservadoras en la educación venezolana, implica un ejercicio introspectivo complejo y vasto, más aún cuando este propósito obedece a la necesidad de construir un epítome sobre el tema. Implica así, situar algunos rasgos históricos fundantes y hurgar someramente en la construcción histórica de la modernidad como fenómeno epocal que trastoca las raíces profundas de las sociedades en cuyo origen emerge la polaridad conservadurismo - liberalismo, en el complejo tránsito secular de la naciente sociedad americana.

Enrique Dussel sostiene que:

La Modernidad se originó en las ciudades europeas medievales, libres, centros de enorme creatividad. Pero "nació" cuando Europa pudo confrontarse con "el Otro" y controlarlo, vencerlo, violentarlo; cuando pudo definirse como un "ego" descubridor, conquistador, colonizador de la Alteridad constitutiva de la misma

\footnotetext{
${ }^{3}$ En BERGUCCI, E. Contribuciones del conservadurismo tradicionalista estadounidense a la conformación de las ideas (neo) liberales. Omnia. Año 16, No. 1, 2010, p. 188.

4 Ídem, p. 190.

Educação e Fronteiras On-Line, Dourados/MS, | v. 10, n.30, p. 42-60, set /dez 2020 
Modernidad. De todas maneras, ese Otro no fue "des-cubierto" como Otro, sino que fue "en-cubierto" como "lo Mismo" que Europa ya era desde siempre. ${ }^{5}$

Es decir, este "encubrimiento" al que hace alusión Dussel, da cuenta de una emergencia societaria alienada que deriva del proceso colonizador, de sus formas e instituciones; con éste, también arribó su manto impositivo que pergeñó secularmente los cimentos de las sociedades del "nuevo mundo".

En el contexto Nuestro americano el flujo y reflujo de las ideas conservadoras llegan de la mano del colonizador español, que instala con la autoridad que otorga la espada la sentencia del obispo de Calahorra que, saliendo en defensa de la inquisición, sostiene que: “...la España es católica; la nación entera ha jurado la conservación de la religión de Jesucristo; debe, pues, ésta protegerla, y tiene obligación de proporcionar los medios más conducentes para conservar en su pureza nuestra santa fe..."6; se esgrime así uno de los pilares ideológicos que regirán el comportamiento social del invasor y su relación de sojuzgamiento de los pueblos originarios.

Se traslada a estas latitudes la fórmula Iglesia - Estado (Monarquía) y todas sus prácticas absolutistas para moldear las tierras conquistadas y sojuzgadas, para favorecer los intereses de la metrópolis.

Domingo Alberto Rangel afirmaría, respecto a la nueva realidad que representaba la imposición colonial, que: "Nuestras sociedades nacen así alienadas. Nada les pertenece. Ni su régimen político, ni sus actividades económicas, ni sus fundamentos sociales. Todo es ajeno." ${ }^{, 7}$ De allí el legado cultural - ideológico que orientaría la conducta colectiva de la sociedad emergente, al menos en los primeros tres siglos de tutelaje colonial español.

José Luis Salcedo Bastardo, describe este como "absolutismo político y económico". En este sentido, destaca que:

En lo político, el órgano capital es la monarquía, ilimitada y discrecional, que da su nombre al sistema; a su frente está un personaje que reina y gobierna con prescindencia de cualquier control, dejando intervenir en el gobierno a Consejos y Audiencias que son su hechura. Celosos los reyes de sus facultades, su voluntad es su ley y la ley del Estado; sólo por expresa delegación suya puede alguien dictar normas de derecho. ${ }^{8}$

De lo anterior se resume la idea primigenia que gobierna la imposición política y cultural colonial, cuyos ejes era el continuismo alineado al poder metropolitano, por tanto,

\footnotetext{
${ }^{5}$ DUSSEL, E. 1492. El encubrimiento del otro: Hacia el origen del mito de la modernidad. La Paz: Plural Editores. Facultad de Humanidades y Ciencias de la Educación - UMSA. 1994, p. 7

${ }^{6}$ Citado en Von Beyme, K. El Conservadurismo. Revista de Estudios Políticos (Nueva Época). Número 43, enero - febrero 1985, p. 10.

${ }^{7}$ RANGEL, D.A. Capital y desarrollo: La Venezuela Agraria. Caracas: Universidad Central de Venezuela FACES. 1974, Tomo I, p. 14.

8 SALCEDO BASTARDO, J.L. Historia fundamental de Venezuela. Caracas: Universidad Central de Venezuela - Ediciones de la Biblioteca. 1996, p. 37.

Educação e Fronteiras On-Line, Dourados/MS, | v. 10, n.30, p. 42-60, set /dez 2020 
el mantenimiento del estatus quo que, vinculado “... a la acepción de la jerarquía social y religiosa", 9 definía el orden natural. Por su parte, Manuel Vicente Magallanes sostiene que: "En el principio España trasladó a sus colonias los mismos elementos espirituales que tenían vigencia en su propio territorio."10

Sigue el autor precitado describiendo y aportando claves sobre el panorama cultural $\mathrm{y}$, con ello, el tipo de relaciones de poder trasplantadas a territorio americano, al señala que: "...priva el concepto de sujeción a las autoridades tradicionales, no se acepta el régimen de libre análisis ni la experimentación, se mantienen los principios aristotélicos, el escolasticismo, la doctrina revelada." "11 Más adelante, desarrolla Magallanes con mayor precisión este planteamiento profundamente conservador que se asemeja más, a los acordes del oscurantismo que primó durante la edad media europea, en el que: “...la Contrarreforma, el pensamiento filosófico que prevalece es el de Santo Tomás de Aquino. Tomistas son, pues, las ideas que inicialmente nutren el intelecto de los hombres de Hispanoamérica."12

Expresión de este marco ideológico - intelectual de la época es la sociedad que se conforma. Juan Acuña lo describe de la siguiente forma:

La sociedad colonial se constituyó en estamentos diferenciados uno del otro por rasgos jerárquicos que tenían como premisas fundamentales la propiedad y la dignita. Dichos rasgos normarían la vida social, básicamente hermética en cuanto los factores que regulan la movilidad social y la adquisición de los privilegios monopolizados por la élite de los blancos con cargos políticos y dueños de fortunas derivadas por la herencia y la usurpación. ${ }^{13}$

Estas ideas y prácticas sociales definen el formato de la arquitectura institucional y cultural que se instalada, perfilando un sistema hegemónico de dominación de profundas raíces conservadoras, inmóvil, rígida, además, fuertemente atado a las decisiones metropolitanas.

\begin{abstract}
...los conflictos sociales que se van a ir sucediendo, con la característica de que a medida que la Colonia se define como tal de hecho y no sólo de derecho - la autónoma y eficiente Colonia- se conjugarán y amalgamarán los conflictos provenientes de la situación colonial - de marcado matiz superestructural o político - ideológico - con los que surgen de la organización y vida social mismas - éstos de origen estructural - conjugación ésta que mostrará la crisis de esta sociedad colonial que se ha formado a lo largo de los dos siglos anteriores y que buscará una primera solución en el proceso emancipador. ${ }^{14}$
\end{abstract}

\footnotetext{
${ }^{9}$ Ídem, p. 12.

${ }_{10}^{10}$ MAGAlLANES, M.V. Historia Política de Venezuela. Caracas: Ediciones Centauro. 1988, p. 142.

11 Ídem, p. 142.

12 Ídem, p. 142.

13 ACUÑNA, J. Estigmas y sacramentos durante el período colonial. Tiempo y Espacio. Vol. $22, \mathrm{~N}^{\circ} 57$. Caracas, junio 2012, p. 10.

14 AIZPURÚA, R. El siglo XVIII en la "Venezuela colonial": la sociedad colonial y su crisis. Caracas: Universidad Central de Venezuela. Material mimeografiado (S/f). Pp. 4 - 5. Educação e Fronteiras On-Line, Dourados/MS, | v. 10, n.30, p. 42-60, set /dez 2020 
Es en medio de una progresiva resistencia que, tomará cuerpo a finales del siglo XVIII y que vendría materializarse durante el siglo XIX, la nueva generación de "blancos criollos" influidos por el goteo de textos y documentos con el influjo de las ideas de la ilustración, se conforma en una emergente intelectualidad local cuya apuesta político cultural abogaba por una sociedad más abierta y autónoma respecto a las directrices de Madrid. ${ }^{15}$ De tal manera que, el germen de las ideas ilustradas y liberales, para entonces revolucionarias, inician así su circulación en el tejido social colonial.

Estas generaciones marcaron las líneas políticas del proyecto emancipador, trazaron la ruta de acción en la lucha política que desembocaría en el movimiento independentista que rompe las ataduras del yugo español, abriendo paso a las nacientes repúblicas americanas. En Venezuela, algunos de sus representantes fueron Francisco de Miranda, Simón Rodríguez, Andrés Bello, Vicente Salias, Simón Bolívar, José Félix Ribas, entre otros, que no sólo enarbolan las ideas "nuevas" de la ilustración y el liberalismo, sino que lo encarnan en su ideario político emancipador.

Tal es así que, en el seno del proyecto emancipador se enraízan las ideas políticas y, particularmente, educativas, ilustradas y liberales. Guillermo Luque sostiene que El Libertador Simón Bolívar "...pensó la educación como fundamento cultural del proyecto republicano. Admitió la función transformadora de la educación en el individuo y, sobre todo, en los grandes colectivos humanos de la América..." Esta síntesis queda revelada en el Discurso de Angostura, pronunciado por Simón Bolívar el 15 de febrero de 1819.

Al frente de las instituciones coloniales se colocaba la Iglesia, la burocracia real instalada y las casas comerciales que tributaban monopólicamente a los intereses de la metrópolis española. Este hecho avizoraba los futuros conflictos entre la Iglesia y el Estado emergente que van a definir la historia de las nacientes repúblicas y que se manifiesta de manera especial en el contexto venezolano.

Al respecto, Antonio Rangel destaca que:

En los conflictos entre Estado e Iglesia sobresale la exigencia de respeto al hecho preciso de ser católica la religión profesada por la inmensa mayoría del pueblo,

\footnotetext{
${ }^{15}$ Cabe acotar que este proceso ocurre en el contexto de varios acontecimientos que definen el futuro de las entonces colonias españolas. Uno de ellos lo marca la sucesión en la corona y encumbramiento de la dinastía de los Borbones en 1700, cuyo "reformismo" sobre el papel de la corona abre una pequeña hendija en el acorazado armatoste del poder monárquico español, con incidencias posteriores en los dominios allende los mares. Otro aspecto de significativa importancia, es la llegada y establecimiento de la Orden de los Jesuitas en tierras americanas, cuya capacidad organizativa, sobre todo de fundaciones agrícolas y la creaciones escuelas )y universidades), tienen una incidencia cultural notable en la cotidianidad colonial; finalmente, otra realidad que se impone es la del contrabando que, a través de dicha práctica, ingresan al coto cerrado de las colonias libros y otros materiales documentales sobre las ideas de la ilustración y del debate intelectual que ocurre en la Europa que se debate entre la pesada tradición del viejo régimen y las innovadoras ideas liberales sobre el progreso de las sociedades, con la impronta del positivismo.

${ }^{16}$ LUQUE, G. Educación, pueblo y ciudadanía. La educación venezolana en la primera mitad del siglo XX 1899 - 1950. Caracas: Fundación Editorial "EL perro y la rana”. 2010, p. 8.
} 
así sea nominalmente, y de estado de alienación religiosa inherente a la práctica de cualquier creencia religiosa. El condicionamiento mental surgido de la fe, diligentemente administrado por las organizaciones eclesiales de todo signo, deviene en fuerza mental superior indiscutible que rige la conducta y el pensamiento humanos. ${ }^{17}$

Sin embargo, recuerda Perú de Lacroix en el Diario de Bucaramanga, que el Libertador Simón Bolívar con sentido premonitorio, en el fragor de la Convención de Ocaña, describía el comportamiento ambivalente, contradictorio, de los poderes hegemónicos en los primeros trances de la República respecto al ideario emancipador y las prácticas, cuando observaba que:

...en Colombia hay una aristocracia de rango, de empleos y de riqueza, equivalente, por su influjo, por sus pretensiones y peso sobre el pueblo a la aristocracia de títulos y de nacimiento la más despótica de Europa. En aquella aristocracia entran también los clérigos, los frailes, los doctores o abogados, los militares y los ricos; pues aunque hablan de libertad y de garantías es para ellos solos que las quieren no para el pueblo que, según ellos, debe continuar bajo su opresión; quieren también la igualdad, para elevarse a los más caracterizados, pero no para nivelarse con los individuos de las clases inferiores de la sociedad: a éstos los quieren considerar siempre como sus siervos a pesar de todo su liberalismo. $^{18}$

\section{La República en sus inicios}

Cuando la mayoría de los procesos independentistas habían logrado el objetivo político de desvincularse de España una vez roto el proyecto bolivariano de unidad de la Gran Colombia, resurge con fuerza en Venezuela la disputa por el poder entre las oligarquías locales y los sectores sociales encumbrados durante la guerra, fundamentalmente, militares. Los comerciantes de todo tipo y ralea, aprovechan entonces la menguada economía nacional para sacar réditos de la situación de caos reinante.

Las facciones en pugna se agruparon en dos grandes campos político - ideológico, a saber: el de los conservadores y liberales. ${ }^{19}$ A partir de esas adscripciones, se organizaron los partidos políticos, en principio, en torno a los intereses de los grupos en pugna: a) aquellos que aspiraban la desvinculación de España, manteniendo los privilegios de otrora; y b) los que reivindicaban la gesta libertadora de Bolívar y la construcción de la "república de iguales"; en ello se incluía una profunda reforma agraria y liberación de los esclavos. De este amplio espectro ideológico podían destacarse diferentes matices, más allá de esta polaridad de intereses que variaban según las situaciones y contextos en los que se

\footnotetext{
${ }^{17}$ RANGEL, A. Luces y sombras. Iglesia, poder y Estado en Venezuela. Caracas: Instituto de Altos Estudios del Pensamiento del Comandante Supremo Hugo Chávez Frías. 2016, p. 29.

${ }^{18}$ LIÉVANO, Aguirre, I. Bolívar (1783 - 1830): El visionario de la Gran Colombia y el Panamericanismo. New York: Ediciones LAVP. 2017, p. 394.

${ }^{19}$ Cabe señalar que en nuestro caso, pese al influjo político cultural que tuvo en el país estas manifestaciones político - ideológicas, en la práctica social se observaba un sinnúmero de situaciones que hacían referencia a la permeabilidad social situada en la adscripción a cada uno de esos espacios de poder.
} 
planteaba la disputa. También, cabe reconocer que es a partir de estas aspiraciones que se emplearon diferentes argumentos para disputar la razón material del poder.

De acuerdo con José Luis Romero, "El núcleo original del pensamiento conservador perpetuaba las ideas de la antigua sociedad colonial, una sociedad barroca constituida por dos grupos netamente diferenciados: los que gozaban de privilegios y los que no los tenían." 20 Ahora, en el nuevo escenario político e institucional que propiciaba la naciente república, eran movidos por el temor de los mantuanos ${ }^{21}$ y comerciantes a los cambios que parecieran vislumbrarse en el horizonte. En este sentido, sigue el autor afirmando que, las fuerzas conservadoras:

Percibirán precozmente la amenaza que puedan entrañar ciertos cambios - y a la larga sus fundamentos, si esos cambios llegaran a prosperar -, aquellos que estén indisolublemente ligados a las estructuras tradicionales y a sus fundamentos (p. XVI).

De allí que una caracterización de este poder concentrado de profundo arraigo en la sociedad, la aporta el mismo Romero al definirlos como:

... aquellos a quienes los ata una consustanciada tradición, importantes intereses económicos, un modo congénito de mida, vigorosos prejuicios y, sobre todo, la convicción profunda de ser herederos históricos y mandatarios de quienes establecieron - de manera tácita o expresa - aquellos fundamentos al instituir las estructuras originarias de la sociedad. ${ }^{22}$

Por tanto, el proceso independentista representó para estos grupos una real amenaza a su secular "tranquilidad", a su posición hegemónica asumida por "derecho natural", como se señala previamente. Y es el campo de la educación y la cultura, uno de los territorios en los que de manera enconada se presenta esta colisión de intereses. Una de las razones fundamentales es que este campo es considerado históricamente un coto privilegiado del pensamiento conservador representado en la práctica por la jerarquía eclesiástica. El caso venezolano no es la excepción.

La etapa republicana que se inicia en 1830, caracterizada por la materialización de la fragmentación de la Gran Colombia y la vía independiente de Venezuela separada del proyecto original de Simón Bolívar, abre un ciclo de reordenación institucional y de reagrupación de los diferentes grupos de poder; es tiempo de conformación de los partidos conservador y liberal. José Antonio Páez, héroe de la independencia, es aupado por los sectores conservadores de la excolonia convirtiéndose en presidente de la república.

\footnotetext{
${ }^{20}$ Ídem, p. XVI.

${ }^{21}$ Era la clase social o casta compuesta por los blancos criollos, descendientes directos de los colonizadores españoles, que constituían una suerte de aristocracia local.

${ }^{22}$ ROMERO, J.L. El pensamiento conservador Latinoamericano en el siglo XIX. Prólogo. Caracas: Biblioteca Ayacucho.
} 
El proceso constituyente de ese año del cual surge la Constitución que regirá los destinos de la nueva república, otorga el piso político que consolida el ejercicio de gobierno de Páez.

La república convirtió a los antiguos poseedores de tierra y minas, acostumbrados al ejercicio ilimitado de su autoridad social, en una oligarquía política cuyas tendencias autoritarias canalizaron hacia el apoyo de un poder fuerte, aunque fuera centralizado y unipersonal, con la condición de que representara una garantía de la conservación del orden socioeconómico tradicional. Tal fue el fruto de su actitud pragmática, indisolublemente asociada al anhelo radical de no innovar ni permitir, siquiera, que se prepararan los fundamentos de un nuevo orden igualitario preñado de amenazas para el futuro. ${ }^{23}$

Este marco político, jurídico y social garantizó a los antiguos terratenientes y propietarios preservar las condiciones y posiciones económicas favorables de antaño. Lo paradójico del caso es que, mediante una legislación liberal, como fue la Ley de Contratos de 1834 fundamentada en el librecambismo, se abre paso a una etapa de especulación comercial que favoreció las posiciones de comerciantes, financistas, especuladores de todo tipo y, por supuesto, de los terratenientes más poderosos, consolidando el dominio de los sectores conservadores. De acuerdo con García Torres, Fermín Toro, pensador liberal reconocido de la época, en una evaluación del impacto de esta ley concluyó que: “...con datos empíricos en mano, la ley del 10 de abril de 1834, que en verdad había terminado siendo un instrumento favorable a la usura y no de amparo o de apoyo al pretendido desarrollo."24

Es en este contexto convulso, de forcejeos por el poder político, entran en escena las ideas liberales corporizadas en la vida política e intelectual de la república fundamentalmente expresadas en la praxis económica de los poderes constituidos. Los gobiernos conservadores de Páez, Vargas y Soublette, dan paso a planteamientos modernizantes (o al menos aspiran a ellos), de corte liberal de la mano de las contribuciones derivadas de la incipiente penetración de las ideas positivistas en Venezuela. Vargas, luego de una breve pasantía al frente de la presidencia de la república (1835 1836), asume la Dirección General de Instrucción Pública en 1838, encuentra a la institución, en palabras de Luque, que “...prácticamente todo estaba por hacer, pues predominaban en el panorama institucional educativo las Escuelas de Primeras Letras y las universidades. Ni existían los colegios ni había relación de continuidad entre las instituciones educativas existentes." 25

Vargas imprime su orientación política filosófica respecto a la educación. En este sentido, continuando con Luque: “...Vargas toma la idea de la educación popular y se muestra como ideólogo de la educación. Propone una educación popular con una escuela elemental, básica, gratuita y obligatoria."26 Destaca, en primer lugar, que en la agenda de un gobierno conservador se postulase fundamentos liberales e incluso, revolucionarios para

\footnotetext{
${ }^{23}$ Ídem, p. XVIII.

${ }^{24}$ GARCÍA TORRES, R. Fermín Toro: Teoría racional de la sociedad y republicanismo cívico. Utopía y Praxis Latinoamericana. 2007, vol.12, n.36, p. 80

25 Ídem, p. 10.

26 Ídem, p. 11.

Educação e Fronteiras On-Line, Dourados/MS, | v. 10, n.30, p. 42-60, set /dez 2020 
la época, que iban a contracorriente de las aspiraciones hegemónicas del status quo imperante. Concluye Luque que, Vargas se topó con dificultades para materializar estas ideas, puesto que: “...no contó con el apoyo de la élite de propietarios de la tierra, de las haciendas, de los mantuanos que, por lo general, eran los mismos que manejaban el sistema político." 27

Un segundo asunto que se desprende de la lectura anterior y quedará reflejado a lo largo de la historia republicana, es una suerte de transversalidad ideológica respecto a las ideas liberales entre grupos que se autodefinen como "conservadores" y otras veces "liberales". Es decir, posturas discrecionales en relación a los aspectos y temas que favorecían o no los intereses hegemónicos de las élites.

El educador colombiano Miguel Antonio Caro, referente del pensamiento conservador en su país, afirmaba que:

La educación popular es, para nosotros —escribía - científica en su materia, pero religiosa en su forma, y no podemos admitir la separación que se intenta hacer de forma y materia en negocio tan importante. Quitarle su forma a la educación, aunque subsista la materia, es adulterar, destruir la educación. La educación popular, así mutilada y viciada, es una educación falsa y corruptora que ni el nombre de educación merece. La educación del hombre, como el hombre mismo, tiene alma y cuerpo. Educación sin religión es hombre sin alma: cadáver y putrefacción. ${ }^{28}$

Caro sintetiza así la doctrina que caracterizará la pretensión conservadora de monopolio de la educación, como un coto privado de la Iglesia y de las élites aliadas, exclusivo también de la acción evangelizadora emprendida durante el proceso colonizador. Al mismo tiempo, devela los nudos conflictivos con las ideas liberales sobre el tema educativo cuyas aspiraciones apuntaban hacia su secularización, con un evidente protagonismo y control público sobre ésta.

Más aún, en un ambiente intelectual de mediados de siglo XIX, progresivamente impregnado por el positivismo que se erigía como referente discursivo innovador, tanto en el ámbito académico como en el político, para oponerse a los tradicionalismos y de la ortodoxia católica. Rafael Villavicencio, científico, académico universitario y personalidad reconocida entre la intelectualidad nacional, es el precursor de las ideas positivistas en el país, también un animado difusor de estos planteamientos en el mundo académico venezolano.

Las refriegas políticas que ocupan la vida nacional y que se expresan en la guerra federal que enfrenta a conservadores y liberales durante lo que queda del siglo XIX. Este hecho coloca el tema educativo en un lugar lejano de las prioridades políticas, hasta la asunción a la presidencia de Antonio Guzmán Blanco, quien en 1870 promulga el Decreto de Educación Popular, Gratuita y Obligatoria. Esta decisión normativa profundiza el conflicto preexistente con las fuerzas conservadoras nucleadas en torno al poder eclesial.

\footnotetext{
${ }^{27}$ Ídem, p. 11.

${ }^{28}$ Ídem, p. XXXV. Educação e Fronteiras On-Line, Dourados/MS, | v. 10, n.30, p. 42-60, set /dez 2020
} 
Entre otras razones, porque iba incluida en el marco de una política dirigida a secularizar la sociedad, por tanto, la escuela, desplazando la influencia de la Iglesia católica del control de la educación pública nacional.

Otro evento de significativa importancia lo constituye la organización del Primer Congreso Pedagógico Nacional, evento realizado entre el 28 de octubre y el 17 de diciembre de 1895. Este encuentro es presidido por el precitado Dr. Rafael Villavicencio, académico vinculado al movimiento positivista en el país. Como dato significativo de las deliberaciones de esta reunión, destaca la confrontación ideológica entre librepensadores y destacados participantes que esgrimían las ideas positivistas con representantes "...defensores del tradicionalismo, de la ortodoxia católica, apostólica y romana.",29

Esta confrontación de enfoques la resume Guillermo Luque de la siguiente manera:

De un lado, los partidarios del naturalismo, del evolucionismo, del laicismo, de la reforma educativa; si no en contra, al menos sí al margen del dogmatismo católico. De otro, los partidarios del creacionismo, de la enseñanza del dogma católico incluso en las escuelas públicas. ${ }^{30}$

Tales planteamientos constituyen, grosso modo, los ejes doctrinarios que van a guiar el conflicto ideológico entre los sectores confrontados en el albor del siglo XX. Pese al encumbramiento de las élites liberales en posición de influencia en la larga de dictadura de Juan Vicente Gómez que se mantuvo en el gobierno durante las primeras tres décadas del siglo, la influencia de los sectores conservadores anclados en diferentes instancias del poder seguía siendo determinante.

Producto de esa influencia en los círculos de poder gomecista se fragua la decisión de revocar el Decreto de Educación Popular, Gratuita y Obligatoria de la época de Guzmán Blanco y el Código de Instrucción Pública ${ }^{31}$ promulgado por Joaquín Crespo en 1897. Esta contrarreforma educativa $^{32}$ estuvo dirigida a favorecer los intereses privados defendido por la élite conservadora secular, aunque el poder eclesial no estuvo satisfecho porque, entre otras razones la nueva norma no respetaba "el principio" de "libertad de enseñanza".

Mariano Picón Salas, reconocido intelectual venezolano de la época, afirmaba que: “... con el final de la dictadura gomecista comienza apenas el siglo XX en Venezuela. Comienza con treinta y cinco años de retardo." ${ }^{33}$ Describía así la situación del país, asolado primero por la guerra federal y la pesada carga económica que acarreó, luego por los

\footnotetext{
${ }^{29}$ Ídem, p. 23.

${ }^{30}$ Ídem, p. 23.

${ }^{31}$ De acuerdo con CARVAJAL RUIZ, S.H. y VILLASMIL SOCORRO, P.E., se trata de una norma que “....aparte de incorporar aspectos ordenadores y funcionales del incipiente sistema educativo nacional, constituyó otro punto de inflexión importante en los desencuentros históricos entre el poder constituido y la Iglesia Católica. El Artículo 17 del mencionado instrumento jurídico relega a un papel optativo la formación religiosa..." (p. 64)

${ }^{32}$ Con la promulgación de la Ley Orgánica de Instrucción Pública de 1924.

${ }^{33}$ PICÓN SALAS, M. La aventura venezolana. Suma Venezuela. Caracas: Fundación Editorial "El perro y la rana", 2012, p. 24

Educação e Fronteiras On-Line, Dourados/MS, | v. 10, n.30, p. 42-60, set /dez 2020 
gobiernos de fuerza que la sucedieron ${ }^{34}$ hasta 1935 , evidenciando las secuelas sociales, económicas y políticas de proyectos nacionales fallidos en permanente redefinición.

Ubicado en el periodo de entre guerras ${ }^{35}$, Venezuela está en vías de consolidarse como un país monoexportador de hidrocarburos, producto de un proceso acelerado de modificación de la matriz económica. Esta transformación opera desde una matriz preponderantemente agrícola y rural hacia otra de carácter exportador minero extractivo, con una creciente configuración demográfica urbana. Esta emergente realidad redefine en el corto plazo el rol del país en la geopolítica regional como pieza clave en el sistema mundo capitalista. También, tuvo importantes repercusiones en la hacienda nacional que, pasa de un mermado presupuesto producto de una empobrecida economía dependiente de la actividad agrícola y pecuaria, a otra impulsada por la exportación de hidrocarburos.

Este tránsito tiene especial repercusión en la conducción política del país con incidencia en la recuperación progresiva de ciertas libertades civiles y políticas. El postgomecismo es gestionado por hombres de confianza del régimen, como es el caso del general Eleazar López Contreras que asume la presidencia de la república hasta 1941, cuando lo sucede Isaías Medina Angarita, esta vez electo por el congreso nacional. De acuerdo con Luque, el gobierno de Medina Angarita se afirmó: “...en los principios de la democracia liberal restringida. Con él, el país experimentó un ensanchamiento de las libertades." 36

La legalización de organizaciones políticas ${ }^{37}$ era muestra de la apertura política. La economía nacional mejora; este progreso se observa en el incremento del ingreso nacional por concepto de la exportación de hidrocarburos, como consecuencia de la Reforma Petrolera de 1943. Esta modificación de la ley permitió mayores regalías al fisco de la nación. Un dato curioso es que, pese a la adscripción liberal del gobierno, el Estado es factor clave en el desarrollo de la agenda política, económica y social del país.

En el ámbito educacional, se ponen en evidencia las diferencias en los enfoques y perspectivas teóricas entre los sectores en pugna. Primero, con López Contreras se promulga la Ley de Educación de julio de 1940; con ello se cierra el ciclo de la ley gomecista de 1924. La normativa de 1940, enfatiza la presencia del Estado en la inspección, en el diseño e implementación del currículo, así como en el otorgamiento de certificados y títulos. Asimismo, el espíritu de la ley contempla la gratuidad de la educación pública más allá de la Educación Primaria Elemental. Como segundo elemento, fue la contundente oposición conservadora nucleada nuevamente en torno a la Iglesia Católica que se empeñaba en exigir la "libertad de enseñanza" absoluta. Esta moción, pese a los litigios, finalmente no tuvo recorrido al ser rechazada por la Corte Federal y de Casación. Y un tercer aspecto significativo es el relativo a la afluencia de nuevas ideas pedagógicas, fundamentalmente de los aportes intelectuales derivados de la innovadora Escuela Nueva, que llega al país por, entre otros canales, la Misión de Pedagogos Chilenos. ${ }^{38}$

\footnotetext{
${ }^{34}$ Antonio Guzmán Blanco, Cipriano Castro y Juan Vicente Gómez.

${ }^{35}$ Se refiere a la I y II Guerra "Mundial".

${ }^{36}$ Ídem, p. 65.

${ }^{37}$ Este contexto se fundaron los partidos políticos Acción Democrática (1942), Acción Nacional (1942), Partido Democrático Venezolano (1943), entre otros.

${ }^{38}$ Ídem, pp. $58-59$.

Educação e Fronteiras On-Line, Dourados/MS, | v. 10, n.30, p. 42-60, set /dez 2020 
Este influjo de enfoques e ideas pedagógicas tiene y tendrán especial repercusión en el desarrollo de la educación nacional, así como en el perfil asumido por el movimiento pedagógico y magisterial. Mientras la educación pública experimenta con esta influencia un renovado impulso en contenidos, métodos de enseñanzas y situaciones de aprendizajes ${ }^{39}$ y avanza la organización de las bases magisteriales, “...lo más avanzado que podía ofrecer la Iglesia Católica en pedagogía era el Ratio Studiorum o Plan de Estudios de la Compañía de Jesús, aprobado en 1599." 40

Luego de los acontecimientos de 1945, que desemboca en un golpe cívico - militar contra el gobierno democrático de Isaías Medina Angarita, asume el control político una junta de gobierno que regirá los destinos de la nación los próximos tres años. Esta junta estuvo integrada, entre otros, por Rómulo Betancourt representante del partido Acción Democrática y, por el sector militar, el mayor Marcos Evangelista Pérez Jiménez.

El petróleo se consolida como elemento clave, motor de la economía nacional. En el campo educativo se incrementa la escolarización, la formación y mejoramiento profesional de los maestros con la creación de los institutos pedagógicos, y se fortalece el papel del Estado como rector de la educación nacional. Este último aspecto queda refrendado como doctrina de la nación con la nueva Constitución de la república, desarrollada en la Ley Orgánica de Educación de 1948. Ambas normativas ofrecen el marco legal y doctrinario del Estado Docente. Establece, entre otros temas relevante, que la educación constituye una de sus funciones insoslayable. ${ }^{41}$ Además, contempla el reconocimiento a la "libertad de enseñanza" y el estímulo de la educación privada por parte del Estado.

El golpe de Estado del año 48, revierte todo este proceso dirigido a abrir otros escenarios de desarrollo a la educación nacional, en el que en la breve etapa que culmina, se hizo énfasis en la democratización del acceso a la educación, en el laicismo y un protagonismo marcado de la acción pública.

El régimen dictatorial emprende la derogación de la Ley de Educación de 1948, sustituyéndola por el Estatuto Provisional de Educación a la medida de los intereses que defendían los golpistas, que mantiene su vigencia hasta la aprobación de una nueva ley en 1955. Es decir, posponen la doctrina del Estado Docente que favorece abiertamente la apuesta político ideológica de la Iglesia Católica y los intereses privatizadores de la educación en general. ${ }^{42}$ Este hecho es reconocido por un escribiente defensor de la educación confesional, como es el caso de Javier Duplá para quien "La dictadura perezjimenista significó para la educación católica un período de crecimiento y de buenas relaciones con el gobierno." ${ }^{43}$

La recomposición de la situación política del país durante el régimen democrático representativo luego de diez años de dictadura, abre un nuevo ciclo en el proceso educativo nacional. Cabe mencionar que con la nueva constitución que emerge del proceso constituyente de 1961, se reivindica la doctrina educativa del año 48, de manera especial lo

\footnotetext{
${ }^{39}$ Producto de los aportes intelectuales y experiencias pedagógicas de Pestalozzi, Decroly, Dewey, entre otros.

${ }^{40}$ Ídem, p. 61.

${ }^{41}$ Ídem, p. 69.

${ }^{42}$ Ídem, p. 70.

${ }^{43}$ DUPLÁ, F.J. 75 años de la educación venezolana. Revista Sic, abril 2014, p. 119. Educação e Fronteiras On-Line, Dourados/MS, | v. 10, n.30, p. 42-60, set /dez 2020 
referido al carácter rector del Estado en la educación nacional. En este orden de ideas, se contempla la gratuidad y obligatoriedad de la educación pública, ${ }^{44}$ así como se abre la posibilidad de cobrar la matrícula en la educación pública universitaria y en la modalidad de educación especial.

Otro elemento a destacar es que: "Pese a este nuevo marco constitucional, la Ley Orgánica de Educación de 1955 siguió en vigencia por espacio de casi tres décadas, cuando en julio de 1980 se promulga el nuevo marco normativo para la educación venezolana." ${ }^{45}$ Éste no es un dato menor porque revela el pacto de las élites con los nuevos actores políticos ahora en el poder; a la par, viene a presagiar el diseño de la arquitectura política y las relaciones de poder sobre el que transitaría la nación en las próximas décadas.

Bajo el paraguas del pluralismo político - ideológico el régimen de la IV República $^{46}$ abre las compuertas de la privatización de la educación, convirtiendo en "servicio" lo que representó una conquista social, pública, como es el derecho a la educación pública, así como el valor de la gratuidad. Este fenómeno ocurre en el contexto geopolítico de la depreciación de las tesis keynesianas fundamentadas en el Estado del bienestar, y la instalación del relato sobre la "crisis de la democracia" fundamentado en el "fracaso" de los Estados en la gestión de lo público, en las "pocas" libertades económicas, que sirven de piso y sustento del neoliberalismo como dogma de fe hasta nuestros días.

Tras décadas de forcejeo, los apóstoles del libre mercado ganan terreno: la acción pública, es decir, de la política de Estado se percibe sospechosa, burocrática y perniciosa; sobre ésta se concitan todos los males que ocurren en la complejidad social y, por supuesto, es el Estado es el principal responsable de la ruina de las sociedades. Estos nudos críticos, según el relato neoliberal, sólo serán superados con el concurso del mercado como actor económico de primer orden. La política es cuestión de gerentes.

El golpe de Estado contra el presidente Salvador Allende en septiembre de 1973, inaugura la andadura del neoliberalismo en Nuestra América. En la década de los años 80 experimenta su expansión y desarrollo hasta entrados de los 90. La agenda política neoliberal enfatizó en los llamados "ajustes estructurales" dirigidos a achicar el tamaño del Estado, transferir competencias públicas al sector privado mediante procesos de tercerización, o "liberalización” de los servicios, entre ellos la educación.

La erosión sostenida de derechos fundamentales como la salud y la educación, mediante la reducción de la inversión social deja al descubierto las falencias de un sistema político y social que, en su conjunto, tributa en la agudización de los índices de pobreza y exclusión, llegando revelar indicadores que presagiaban una catástrofe política.

Los herederos de los forjadores del "Estado docente" son ahora sus aniquiladores. La privatización educativa gana terreno bajo los relatos de la calidad y la eficiencia frente al "desastre" inducido de la escuela pública. En este contexto se promulga la Ley Orgánica

\footnotetext{
${ }^{44}$ Ídem, p. 72.

${ }^{45}$ Ídem, p. 72.

${ }^{46}$ Hace referencia al periodo gobernado por los partidos vinculados al Pacto de Punto Fijo, acuerdo político firmado por las élites político - empresariales del país bajo el tutelaje de los EE.UU.; este momento está comprendido entre 1958 y 1998. Culmina con el triunfo electoral del presidente Hugo Chávez y el proceso constituyente liderado por éste en 1999.

Educação e Fronteiras On-Line, Dourados/MS, | v. 10, n.30, p. 42-60, set /dez 2020 
de Educación de 1980 que, pese a reeditar la vieja aspiración de la rectoría pública sobre la educación a través de la figura del Estado docente, en realidad ofrece el escenario normativo para la expansión del neoliberalismo educativo, como sinónimo de la privatización.

La implementación y desarrollo de la agenda neoliberal abre un periodo de grandes conflictos en la región. El incremento de la pobreza como manifestación de la configuración de sociedades profundamente desiguales, son el abono a una etapa de conflictividades que se expresan, por ejemplo, en el Caracazo en febrero de 1989, el levantamiento popular en Caracas que impugna el "paquete" de medidas neoliberales contenidas en el "programa de ajustes macroeconómicos" impuestas en el recién iniciado gobierno de Carlos Andrés Pérez.

Este hito histórico es la compuerta para la emergencia de otras situaciones políticas y con ellas, otros actores políticos. La rebelión del 4 de febrero de 1992 ofrece al país un escenario político novedoso, que se materializa en las elecciones de diciembre de 1998, en la que es elegido Hugo Rafael Chávez Frías presidente de la república. Se inicia de esta manera la recomposición de las estructuras del Estado y de la sociedad en general, estimulado por el proceso constituyente que desembocó en la constitución de 1999.

Ante un hecho tan transcendental como la constituyente que genera un movimiento telúrico en todos los estamentos políticos, económicos, sociales y culturales del país, los factores representantes de la vieja política se reagrupan para confrontar “...por todas las vías, recursos y argumentos, toda acción de gobierno."47

Nuevamente el espacio educativo - cultural, junto al económico, será uno de los escenarios en que se librará la confrontación. Se reeditan aquí las coaliciones contrarias al papel del Estado en la rectoría de la educación, con el reagrupamiento de sectores conservadores, eclesiásticos, fundamentalistas neoliberales y/o empresarios de la educación. Toda esta amalgama de intereses se confabula contra la doctrina constitucional en materia social y cultural. La inclusión social y las políticas redistributivas constituyen los anatemas contra los que se confabulan con renovado impulso las fuerzas conservadoras, revestidas con un aire de "modernidad".

\section{CONSIDERACIONES FINALES}

El breve recorrido realizado subraya la mutación ideológica del conservadurismo hasta abrazar al neoliberalismo económico, pero manteniendo las viejas ataduras de la tradición y la costumbre como correaje cultural, garantía de la obediencia debida a los designios del capital antes desdeñado. En este proceso toma para sí la defensa de la "libertad" contra las "dictaduras populistas". Cabe recordar de la mano Bernat Muniesa ${ }^{48}$ al florentino Nicolás Maquiavelo aquello que "...donde hay poder no puede haber libertad"; se puede agregar entonces que, donde gobiernan las leyes del mercado capitalista tampoco puede haber democracia.

\footnotetext{
47 Ídem, p. 75.

${ }^{48}$ MUNIESA, B. Libertad, liberalismo, democracia. Barcelona: El viejo topo. 2008, p. 15. Educação e Fronteiras On-Line, Dourados/MS, | v. 10, n.30, p. 42-60, set /dez 2020
} 
En la práctica materializan el ideario fusionista entre el tradicionalismo propio de los conservadores seculares con la perspectiva económica del neoliberalismo en nuestros días. La bandera de la libertad por un lado, pero por la otra, en el mundo material, la negación de facto de la democracia y sus expresiones en la pluralidad social actual, mediante el férreo control del "mercado". En este juego de palabras y relatos, las hegemonías culturales confunden intencionadamente libertad con liberalismo, democracia por mercado. En este contexto, la educación no deja de ser un escenario de esta confrontación.

\section{REFERENCIAS}

ACUÑA, Juan. Estigmas y sacramentos durante el período colonial. Tiempo y Espacio. v. 22, n.57. Caracas, junio 2012, pp. $9-30$.

AIZPURÚA, Ramón. El siglo XVIII en la “Venezuela colonial”: la sociedad colonial y su crisis. Caracas: Universidad Central de Venezuela. Material mimeografiado (S/f).

BERGUCCI, Emmanuel. Contribuciones del conservadurismo tradicionalista estadounidense a la conformación de las ideas (neo) liberales. Omnia. Año 16, n.1, 2010, pp. $180-203$.

CARVAJAL RUIZ, Samuel H. y VILLASMIL SOCORRO, Paulina E. La educación venezolana en el contexto de desarrollo de las tensiones entre lo público y lo privado. En Vidal Peroni, V., Valim de Lima, P. y Kader, C. Redefinición de las fronteiras entre o público e o privado. Sao Leopoldo (Brasil): Oikos Editora, 2018.

DUPLÁ, Francisco Javier. 75 años de la educación venezolana. Revista Sic, abril 2014, p. $115-126$.

DUSSEL, Enrique. 1492. El encubrimiento del otro: Hacia el origen del mito de la modernidad. La Paz: Plural Editores. Facultad de Humanidades y Ciencias de la Educación - UMSA. 1994.

GARCÍA TORRES, Rafael. Fermín Toro: Teoría racional de la sociedad y republicanismo cívico. Utopía y Praxis Latinoamericana. 2007, v.12, n.36, pp. 77-89.

LIÉVANO AGUIRRE, Indalecio. Bolívar (1783 - 1830): El visionario de la Gran Colombia y el Panamericanismo. New York: Ediciones LAVP, 2017. 
LUQUE, Guillermo. Educación, pueblo y ciudadanía. La educación venezolana en la primera mitad del siglo XX - 1899 - 1950. Caracas: Fundación Editorial "El perro y la rana", 2010.

MAGALLANES, Manuel Vicente. Historia política de Venezuela. Caracas: Ediciones Centauro. 1988.

MARCO, José María. Conservadores, liberales y neoconservadores. Fundamentos morales de una sociedad libre. Cuadernos de pensamiento político FAES. n.8, año octubre diciembre de 2005, pp. $129-140$.

MUNIESA, Bernat. Libertad, liberalismo, democracia. Barcelona: El viejo topo. 2008.

RANGEL, Antonio. Luces y sombras. Iglesia, poder y Estado en Venezuela. Caracas: Instituto de Altos Estudios del Pensamiento del Comandante Supremo Hugo Chávez Frías. 2016.

PICÓN SALAS, Mariano. La aventura venezolana. Suma Venezuela. Caracas: Editorial Fundación "El perro y la rana", 2012.

ROMERO, José Luis. El pensamiento conservador Latinoamericano en el siglo XIX. Prólogo. Caracas: Biblioteca Ayacucho, 1986. pp. IX - XXXVIII.

RANGEL, Domingo Alberto. Capital y desarrollo: La Venezuela Agraria. Tomo I. Caracas: Universidad Central de Venezuela - FACES. 1974.

SALCEDO BASTARDOI, José Luis. Historia fundamental de Venezuela. Caracas: Universidad Central de Venezuela - Ediciones de la Biblioteca, 1996.

VON BEYNE, Klaus. El Conservadurismo. Revista de Estudios Políticos (Nueva Época), n. 43, enero - febrero, 1985.

\section{FUENTES WEB CONSULTADAS}

https://www.nytimes.com/es/2018/02/07/espanol/opinion/opinion-waisbord-nuevoconservadurismo-cultural-religion-estado-laico.html http://www.fundacionspeiro.org/verbo/1965/V-32-P-101-111.pdf 
DOI: 10.30612/eduf.v10i30.11905

ISSN: 2237-258X

Recebido:11/05/2020

Aprovado: 15/07/2020

Educação e Fronteiras On-Line, Dourados/MS, | v. 10, n.30, p. 42-60, set /dez 2020 